\title{
A systematic review of environmentally conscious product design
}

\author{
Zhongkai Li \\ School of Mechatronics Engineering, \\ China University of Mining \& Technology, \\ 221116 Xuzhou, China \\ lizk_0202@163.com
}

\author{
Jorge Marx Gómez, Alexandra Pehlken \\ Department of Informatics; Cascade Use group, \\ University of Oldenburg, \\ 26129 Oldenburg, Germany \\ Jorge.Marx.Gomez@uni-oldenburg.de \\ Alexandra.pehlken@uni-oldenburg.de
}

\begin{abstract}
Recently environmentally conscious product design (ECPD) is highlighted by research community, because of the global conscious about low carbon emission and sustainable development. ECPD cares about the environmental, social and economic impacts of products during their life cycle phases, with the destination to achieve product life cycle design for sustainability. Furthermore, information and communication technologies are important for the implementation of computer-aided eco-design. The theories, methods, software tools about ECPD during 2005 to 2015 were reviewed in this work. Five most related aspects including product eco-design, design for disassembly (DFD), design for recycling (DFR), material selection (MS), and eco-design software tools were analyzed as related categories. Eco-impact assessment was found to be a pre-step in ECPD followed by product eco-innovation. DFD, DFR, and MS helped to improve the energy efficiency and eco-friendliness of products. Eco-design software tools are focusing on CAD-integration, web-based and knowledge base-based characteristics. More eco-design software tools will be developed in specific industries and to handling products with composite materials.
\end{abstract}

Keywords—product eco-design; design for sustainability (D4S); eco-design software tools; state-of-the-art; eco-friendly produts

\section{INTRODUCTION}

Nowadays, global economic development and resources consumption laid greater burdens on society and environment. To achieve sustainable development without harming the sustainable capability of future generations are of seriously concern by scientists in multiple disciplines. Researchers and engineers are focusing on development and implementation of environmentally conscious product design (ECPD). The aim is to lower the life cycle environmental impacts of products. How to design products with minimized ecological (eco-) impacts and maximized sustainability in a closed-loop lifecycle are highlighted by industries around world.

Recently reviews related to ECPD are shown in Table 1 . Though some reviews about eco-design, LCA, DFD, and material selection have been presented, the development of ECPD still need to be analyzed for the state-of-the-art. The aim of this article is to draw a state-of-the-art review for the most related aspects in ECPD. For the range of the research, in one aspect, over $70 \%$ of the product life cycle performance was decided in the design stage. In another aspect, environmentally conscious product manufacturing contains lots of aspects such as machine tools, processes, production planning, and supply chains. It will be difficult to cover eco-design and ecomanufacturing in one review article. Thus, literatures related in eco-design models, methods, and software were focused in this work. Our motivation is to obtain the current state and explore the future research directions for ECPD through literatures reviewing.

Peer-reviewed papers in Web of Science ${ }^{\mathrm{TM}}$ core collection, also known as Science Citation Index (SCI) database were selected. The time period was limited within 2005 to 2015 to control the amount of literatures. The key words with topic containing were as follows: Design for environment (DFE), Environmentally conscious product design, Eco-design, Design for sustainability (D4S), Life cycle design (DFLC), Green modularization (GM), Design for disassembly (DFD), Design for recycling (DFR), Material selection (MS) and eco-design, Software tool and eco-design. Literatures concerning design of electromechanical products were reserved, and eco-design for aspects such as service, processes or society were omitted. Thus, approximate 120 references were classified and reviewed

Table 1 Previous reviews

Scope of reviews in the last ten years in ECPD

Review for Environmentally Conscious Manufacturing and Product Recovery (ECMPRO) between 2000 and 2010 [1]

Eco-design in electronics focusing on materials selecting, concurrent engineering, and e-waste management [2]

Life cycle assessment (LCA) in green chemical process [3] Sustainable life cycle design [4]

Legislation and techniques in design for disassembly (DFD) [5]

Digital tools for material selection in product design [6]

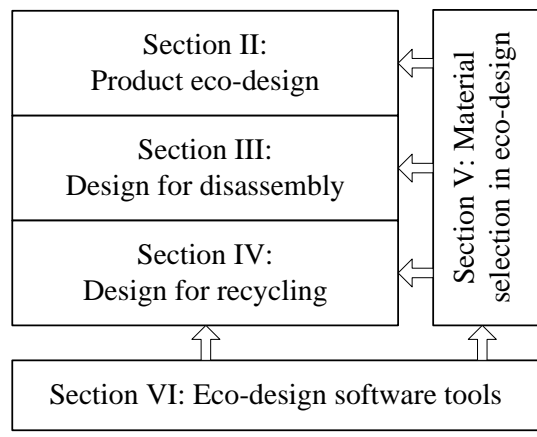

Fig.1. Framework of the research.

This work is financially supported by the National Natural Science Foundation of China under grant 51475459, the Fundamental Research Funds for the Central Universities of China under Grant 2012QNB15, and the Visiting Scholar Foundation from Chinese Scholarship Council (CSC). 


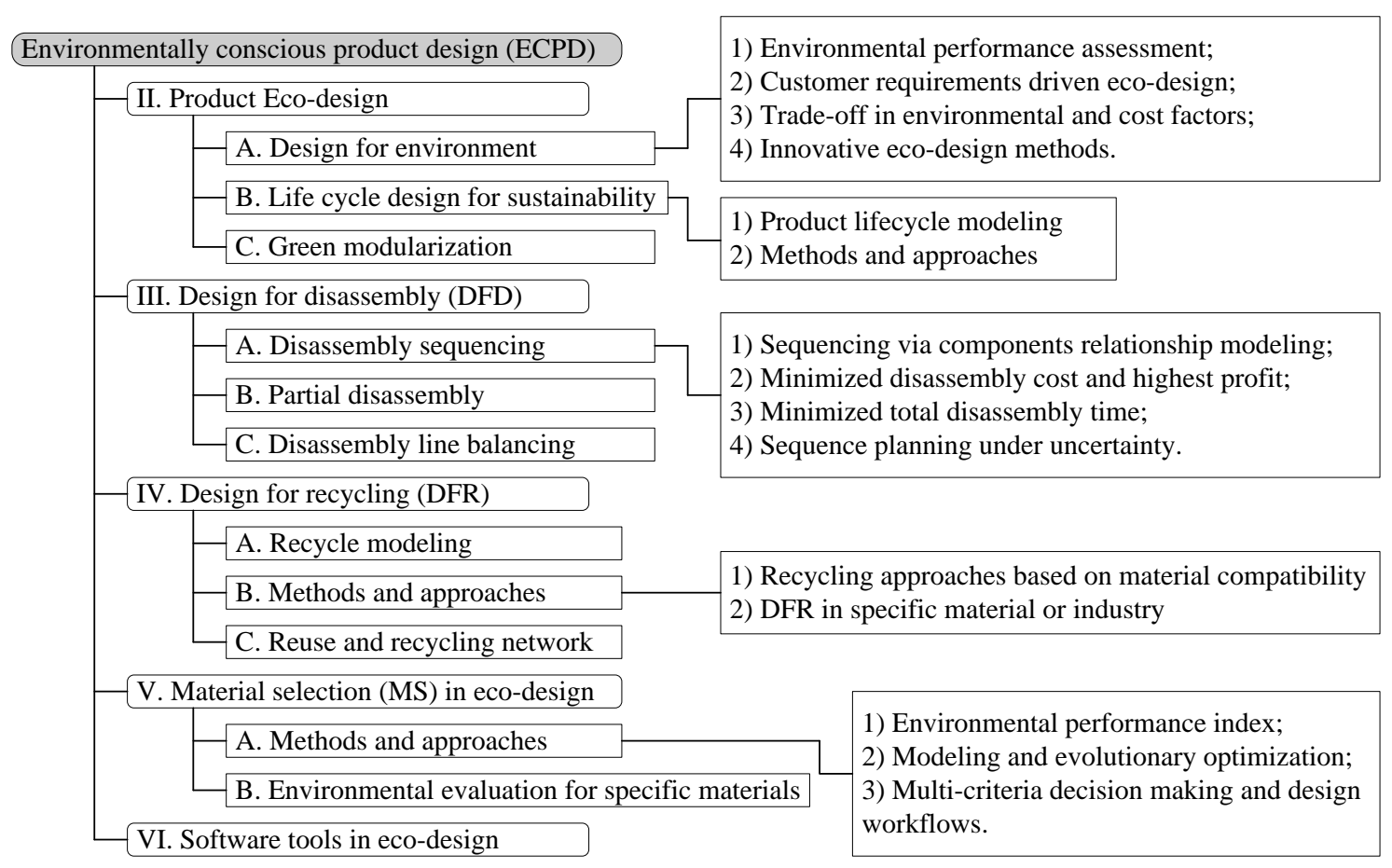

Fig.2. Literatures classification criteria of the research.

The framework of the research is shown in Fig.1. The product eco-design, design for disassembly, and design for recycling are three main parts in ECPD. Also, material selection approaches will guarantee the achievement of the above three parts. Then, eco-design software tools are reviewed as the implementation of the proposed models and methods.

The detailed classification for the literatures is illustrated in Fig.2. A three-level classification rule was applied. At the beginning, literatures were classified according to their features in problem solving, such as eco-design, DFD, DFR, MS, and software. Further, literatures in one aspect were classified with the different problems they solved. For example, papers in DFD were separated into the sequencing, partial disassembly, and disassembly line balancing problems. Finally, in third level, literatures were clustered via their different characteristics in methods. For instance, the research for methods in MS were clustered into eco-performance index based, evolutionary optimization based, and decision making based approaches to ease the analysis. This framework of literatures was benefit for the analysis for detail points and problems, and it could be used to turn to interested points as well.

The rest of paper is organized as follows. Section II reviewed the literatures about product eco-design. Section III discussed the improvements in DFD. Literatures in design for recycling (DFR) and material selection (MS) in eco-design were independently presented in Section IV and V, respectively. Section VI analyzed the development of ecodesign software tools. Section VII summarized the work, and provided research outlooks.

\section{PRODUCT ECO-DESIGN}

\section{A. Design for environment (DFE)}

Quantitatively evaluating the environmental performance of a product is the first step in DFE. Then, DFE methods focusing on customer eco-requirements, trade-off between environment and performance, and eco-innovation are further reviewed.

\section{1) Environmental performance assessment}

A LCA procedure includes (1) Goal and scope definition; (2) Inventory analysis; (3) Impact analysis; and (4) Data interpretation and results. Since the standard LCA needs the design and process data during product life cycle, it is suitable to be used behind the development, manufacturing and use phases. Some techniques and LCA were merged together to increase their availability. For example, a quality function deployment (QFD) and life-cycle impact assessment (LCIA) were combined for quantifying the eco-efficiency [7]. Thus, the requirements satisfaction degree could be evaluated during the ecological assessment process. A series of quantitative ecodesign indicators were proposed to substitute traditional LCIA indicators [8]. These indicators were benefit for specific DFX such as design for disassembly and recycling. A knowledgebased approximate LCA system (KALCAS) [9] was developed to assess the environmental impacts of design alternatives, which provided an intelligent system to ease the LCA work. Moreover, the fuzzy analytical hierarchical process (FAHP) was combined with LCA for the evaluation of green product designs in order to remedy the time-consuming process of traditional LCA [10]. Note that LCA is the most important approach to quantitatively analyze the eco-impact of a product from its life cycle. Because of the complex steps and largescale data preparation in traditional LCA, more simplified LCA methods and computer-aided LCA software were developed to 
assist the eco-impact evaluation of a product. How to assess the eco-impact of a product is the first step to deep into the ECPD.

Multi-criteria decision making (MCDM) approaches were also introduced in the evaluation of product environmental impact. MCDM-based methods are suitable for the ecological evaluation or comparison during product early design stages, in which fuzzy logic, analytical hierarchical process (AHP), and technique for order preference by similarity to ideal solution (TOPSIS) are typical techniques. For instance, AHP was used to weight five aspects including energy, recycling, toxicity, cost and material in a fuzzy logic based ECPD method [11]. Neural networks and TOPSIS were combined together to the evaluation and analysis for DFE [12]. Also, AHP, graph theory, and TOPSIS were integrated to evaluate the green maintenance aspects of mechanical systems at design stage [13]. MCDMbased eco-impact analysis methods usually use evaluation data processing and schemes comparison. This kind of method relies on the subject data from experts, and the final results might exhibit a degree of variation. But it is a supplementary for LCA-based methods when the detailed product and process data are not totally available in early design stage.

\section{2) Customer requirements driven eco-design}

QFD is a method to map the product requirements into techniques and further into components. It is an experience based method to assign the requirements into product model. Thus, environmental requirements were also analyzed by QFD to support eco-design for customer requirements. The product requirements were classified into functional, performance, environmental needs [14]. Then, LCA, QFDE (quality functional deployment for environment) or environmentally conscious QFD (ECQFD), and TRIZ (theory of inventive problem solving) were combined in [15] and [16] to improve product eco-innovation for re-use and recycling. Also, the LCA an eco-design process model, and an enhanced eco-QFD were applied to make eco-design decision making [17]. Further, Rathod [18] presented a case of fuzzy ECQFD to aid product design team in considering eco-concerns. The application of ECQFD will exhibit uncertainties for different problems, because of their different eco-requirements, weights, technical components, and relationship degrees. So how to propose a formal procedure to use ECQFD to map eco-needs to product performance still waiting to be studied.

\section{3) Trade-off in environmental and cost factors}

Multi-objective models about balancing of environment and cost factors have been developed to obtain trade-off between eco-efficiency and profit. Li et al. [19] constructed a multiobjective optimization model for environmentally conscious design for chemical process and products. They made the economic and environmental as two optimization objectives and solved the proposed model with non-dominated sorting genetic algorithm. TOPSIS was introduced to find a best compromised solution from the Pareto optimal set. Su et al. [20] proposed a bi-level optimization procedure to obtain optimized carbon emission and cost of product designs. Further, an evolutionary framework for re-design industrial products based on multiple objective integer programming was presented [21]. Lim et al. [22] constructed a single objective function for ecodesign by enabling the tradeoffs between environmental impacts and economic cost in the same monetary unit. Thus a single design solution could be generated by evolutionary optimization to avoid the diffusion of Pareto solutions. Note that how to modeling the multi-objective problem and solving it to obtain Pareto fronts with global convergence and uniform distribution are two important tasks in this category.

\section{4) Innovative eco-design methods}

Eco-design theories were combined with TRIZ or other new design scheme generating operators to help product ecoinnovation. A life cycle planning framework for innovative eco-design was put forward [23], where the framework combined TRIZ, design uncertainty evaluation, and a product eco-efficiency indicator. A DFE methodology combining back propagation neural networks (BPNN), data envelopment analysis (DEA) and suggestions for improvement tools was proposed [24] to be served as an eco-innovation methodology. Also, an inventive problem solving algorithm based LCE (life cycle engineering) model for innovative product eco-design was put forward [25]. Further, the ECQFD, TRIZ, and AHP were combined to assist innovative and sustainable product development [26]. It is desired that to achieve product ecoinnovation, related methods must contain a conflict solving mechanism, i.e. TRIZ, and DEA, to generate some innovative design schemes for eco-assessment.

\section{B. Life cycle design for sustainability}

Design for sustainability (D4S) requires that the design process and resulting product take into account not only environmental concerns but social and economic concerns as well throughout product life cycle view.

\section{1) Product life cycle modeling}

The interactions or relations among different life cycle phases were modeled. The aim was to provide a dynamic connection for the life cycle factors to assist D4S. Sandberg et al. [27] developed a model for integrating product life cycle factors. The model merged the jet engine design factors such as design, manufacturing, performance, and maintenance. It was by means of knowledge-based engineering system coupled to databases and spreadsheets. Kayis et al. [28] applied the Bayesian Belief Networks to map the inheritance between risk events in product life cycle. Also, a product life cycle model with object-oriented approach was developed [29], where the model contained features in assembly, disassembly, recycling, maintenance, and environment phases. Moreover, patent map was applied to represent the dynamic variation in product life cycle [30]. The knowledge base, Bayesian Networks, objectoriented, or patent map have been used in the life cycle factors modeling. However, how to model the life cycle phases in closed-loop and further apply the model to analyze product design scheme are still difficult work.

\section{2) Methods and approaches}

Some methods and approaches have been proposed for the life cycle D4S. A methodology for product life cycle planning (LCP) with four stages was presented [31], and a software tool was established for eco-design concept of a product. A method to lower the life cycle mismatch considering the cost of mitigating in the design and manufacturing of a product was 
researched [32]. Further, three key eco-design techniques, namely checklists, guidelines, and a material, energy and toxicity matrix were identified [33]. A methodology for identifying environmentally conscious guidelines for product design was put forward using reverse engineering and LCA [34]. Also, the LCA and eco-design approach were used to the sustainability of wood boxes for wine bottles storage [35]. A systematic navigation framework was developed to include the top-down, bottom-up and hybrid styles to implement sustainability in the architecture of a company [36]. Note that product life cycle D4S is somehow overlapped with DFE. Further, D4S not only considers the product eco-performance, but also concerns about its economic and social impacts.

\section{Green modularization}

The aim of green modularization (GM) is to perform modularization not only from functional or structural view, but from product life cycle view to improve EOL (reuse, recycle, remanufacturing) properties of modularized product as well.

Some methods combined the functional, structural, and life cycle factors together in a same level via design structure matrix (DSM) or graph model. The elements were clustered to form modular design scheme with clustering algorithm or group genetic algorithms. Tseng et al. [37] presented a modular design method to support green life-cycle engineering. Yu et al. [38] compromised the relationships among components from function, structure, life time, material and recycling similarities. Then the model was clustered with group genetic algorithm to obtain modularization. The modular results were analyzed by LCA to compare with the initial design scheme to show the effectiveness of GM. In other works, the fuzzy $c$-means and genetic algorithm (GA) were used to clustering the DSM elements [39]. A modular redesign method was described with product environmentally conscious analysis model [40] . Also, a green QFD and DSM based modular product development method was presented [41]. To avoid the infeasibility or suboptimal results in integrated optimization, some constrained modeling and optimization approaches were developed. For example, a product life cycle modularization approach based on self-organizing map and modular density concept [42], an eco-modular design method based structural redesign risk control [43], and a green modularization method involving the effectiveness of multiple life cycle phases [44].

Some green modularization models focused on specific life cycle factors, such as recycling, and supply chain were proposed. A disassembly-oriented assessment method for product modular design was built up [45]. An architecture and supply chain evaluation method [46] was proposed to find a product modular design with both low life cycle costs (LCC) and low energy consumption at the early design stages. Yang et al. [47] proposed a green modularization method for product family considering reuse and recycling abilities. Also, a method to identify remanufacturable modules with boundary modification was presented [48].

It was found that modeling of GM via DSM or graph theory is simpler than GM modeling for specific life cycle factors. To mathematically modeling modularization with one or multiple lifecycle factors, the detailed functions of the factors need to be known. This also improves the modeling complexity. However, specific models are more efficient to generate feasible modular results for different design environments.

\section{DESIGN FOR DISASSEMBLY}

\section{A. Disassembly sequencing}

\section{1) Sequencing via components relationship modeling}

Sequencing is the most important problem in design for disassembly (DFD). Sequencing is to determine the order of disassembly for the parts of a product. The components connection relationship is the first aspect that was considered in sequence planning. Huang and Liao [49] combined the interference, contact and connection matrix to model the relationship among components. They acquired the optimal disassembly sequence with matrix computation. A hybrid graph model was built up for disassembly sequence planning problem [50]. Then, AND/OR graph and physical restrictions among components were used to solve disassembly sequencing problem [51]. For the disassembly problem for configurable products, Qiu et al. [52] presented a modeling approach for configurable products based on disassembly relation DSM. Xia et al. [53] developed the teaching-learning based optimization algorithm for solving the NP-hard disassembly sequence planning problem. Further, the mixed-integer programming was used to partition the Liaison graph of a product assembly with the consideration of the defect rates in components and assembly tasks [54]. Though the AND/OR graph, DSM, and Liaison graph approaches have been implemented to model the elements' relations in sequence planning, the components relations are just basic information in disassembly sequencing.

\section{2) Minimized disassembly cost and highest profit}

Disassembly cost analysis is to let the designers to calculate the cost of product disassembly to help decision making for different disassembly levels and sequencing schemes. Banda and Zeid [55] developed computational algorithms and a graphical user interfaces to enable designers to evaluate disassembly cost in product designs. A probability analysis method of disassembly cost subject to random removal time and different removal labor cost was proposed [56]. In other literatures, minimized disassembly cost and highest profit are aspects that have been considered in DFD sequencing problem. Tripathi et al. [57] proposed a fuzzy disassembly optimization model to determine the optimal sequence as well as the depth of disassembly to maximize the net revenue. Ma et al. [58] pointed out that the disassembly level, sequencing, and EOL options such as reuse, remanufacturing, recycling, landfill, were the three main problems in disassembly research. They developed an extended AND/OR graph and a two-stage algorithm to solve the above three disassembly problems with the objectives of maximized economic profit. The disassembly sequencing with minimized cost will guarantee the economic feasibility of DFD.

\section{3) Minimized total disassembly time}

Some methods calculated the disassembly time and pursued the sequence planning with minimized disassembly time. Go et al. [59] proposed a disassembly sequence planning model 
based on GA for the reuse of automotive components. Their aim was to minimize the total disassembly time. Aiming at the disassembly and reassembly problem in maintenance, Behdad and Thurston [60] proposed an integrated method for disassembly sequence planning for maintenance. They applied the graph based integer programming approach and multiattribute utility analysis to identify the best trade-offs among two factors as follows: the disassembly time under uncertainty and the probability of not incurring damage during disassembly In this category, the analysis of disassembly time requires data such as process time, movement time, and parts' disassembly sequence. Also, obtaining the consumed disassemble time is a basis in disassembly line balancing problem.

\section{4) Sequence planning under uncertainty}

For uncertainties in disassembly process, such as product quantity, and item damaging, some methods modeled the uncertainties in disassembly process to plan robust sequencing. Tian et al. [61] established a disassembly sequence planning model based on the stochastic disassembly network graph and different decision-making criterions. A two-stage robust programming model was developed to disassemble multiple products with a hierarchical structure to satisfy uncertain demands in multiple periods [62]. Behdad et al. [63] proposed an integrating analytical model with the immersive computing technique to help designers overcome the unavailable information in early design stage.

It was noticed that stochastic simulations were always used in uncertainty analysis to guarantee the robust of design results. The computational complexity of stochastic simulation need to be further reduced to ease the industrial application.

\section{B. Partial disassembly}

Partial or selective disassembly sequence planning focused on disassembly one or more selected components from a product for reuse, remanufacturing or maintenance. A method for making decisions of selective disassembly and optimal EOL strategy was proposed [64]. Then, a structured graph based disassembly sequence planning method for selective disassembly problem was researched [65]. Also, Han et al. [66] studied the selective disassembly sequencing problem under the sequential disassembly environment. Further, a genetic algorithm (GA) based heuristic was developed to optimize the partial disassembly sequences for sequence feasibility [67]. Song et al. [68] proposed a disassembly sequence planning method for partial destructive disassembly. Note that partial disassembly approaches are always necessary in high efficient maintenance planning, in order to achieve least maintenance time and cost of products.

\section{Disassembly line balancing}

For the efficient working of disassembly and recycling plants, the disassembly lines are expected to be balanced for different amounts, types, and conditions of products. A multiobjective optimization model was established for a stochastic disassembly line balancing problem (DLBP) with station paralleling [69]. Avikal et al. [70] proposed a Kano model, FAHP, and modified TOPSIS based technique to solve the DLBP under fuzzy environment. Further, Bentaha et al. [71] presented a sample average approximation method for DLBP under uncertainty. Many literatures considered the uncertainties in disassembly line balancing problem. With the infrastructure development of EOL product recycling, DLBP problem will be more focused for actual disassembly plant constructions.

\section{DESIGN FOR RECYCLING(DFR)}

\section{A. Recycle modeling}

The DFR modeling is to model the closed-loop process for material or EOL product recycling. Models with different theories and techniques have been proposed to represent the recycling process. A digital visual simulation method was put forward for design of mineral and metal recycling processes [72]. An agent-based simulation model was presented to modeling both economical and physical relations between firms, recyclers and consumers [73]. The sustainable product design with recycled materials under economic view was also studied [74]. Moreover, material flow analysis (MFA) has been used in recycle modeling [75]. To model the recycling of multiple materials in a product is a focusing point in the future.

\section{B. Methods and approaches}

\section{1) Recycling approaches based on material compatibility}

The material compatibility analysis tools such as metal wheel and material compatibility matrix were developed to help DFR. Schaik and Reuter [76] developed a fuzzy rule based approach to describe the liberation behavior of materials from the recycling rate. Then, they pointed out that the DFR must deep into the material level to analyze the connection type, dismantling, liberation, and extraction performances of different materials [77]. They also developed an easy-to-use model to predict recycling/recovery rates with CAD software [78] as a function of material usage, material combination and joints used. It is noticed that DFR is expected to be combined with CAD to analyze the material compatibility and the cost of EOL recycling processes.

\section{2) DFR in specific material or industry}

Some researchers focused on DFR for specific materials or industry. Table 2 was listed to show the references, concerning materials/industries, and related approaches in this subsection. It can be seen from the table that DFR were always studied in predefined environments, so that the characteristics of the materials or industries can be involved to make the recycling meaningful and more aim-specific.

Table 2 List of DFR in specific material or industry

\begin{tabular}{|l|l|}
\hline Materials/Industries & Related approaches \\
\hline Alloy [79] & Chance-constrained based model \\
\hline Gold [80] & Recycling gold from scrap electronics \\
\hline Composites [81] & Analyze information shares and exchanges \\
\hline Plastic [82] & Plastic product design in sustainability \\
\hline Metal industry [83] & Recycling and implications for emissions \\
\hline Ship industry [84] & $\begin{array}{l}\text { Engineering philosophy targeting sustainable } \\
\text { development }\end{array}$ \\
\hline Auto industry [85] & $\begin{array}{l}\text { Analyzing recycling efficiency of different } \\
\text { material selection }\end{array}$ \\
\hline Packaging [86] & A system dynamics model \\
\hline
\end{tabular}




\section{Reuse and recycling network (RRN)}

Reuse and recycling network is a recent hotspot in product reverse logistics. It cares about the construction of recycling network with minimum expenditure and maximum profit. Erol and Thoming [87] investigated a procedure for synthesizing a RRN for a metal finishing process. Qian and Ji [88] employed a fuzzy programming tool to design the product recovery network considering the uncertainty inherent during the process of practical product recovery. A multi-product recycling network was presented for multiple recoverable material types [89], and a new genetic graphical method for simultaneous targeting and designing of a maximum paper recycling network was also presented [90]. Fröhling et al. [91] applied the MFA method to improve the resource efficiency of the production and recycling network. Vahdani et al. [92] proposed a new mathematical programming model for recycling network design in the iron and steel industry.

Note that the RRN research have focused on the location distribution in a region, recycling plant planning for EOL products, and network planning under uncertainty. With the booming of secondary materials, the reuse and recycling network problem is being increasingly noticed in academia.

\section{MATERIAL SELECTION IN ECO-DESIGN}

Material selection is to select materials and assess the materials combination for components in a product. Optimum materials selection is a very important task in the product design process. Methods of material selection help to guarantee the success of previous product eco-design, DFD, and DFR phases. Thus, literatures about methods, approaches, and ecoimpact analysis for MS were reviewed as follows.

\section{A. Methods and approaches}

\section{1) Environmental performance index}

Quantitatively evaluate the environmental performance of materials is the most important ability of MS approaches. Huang et al. [93] proposed a method for establishing a life cycle environmental performance index. Cui and Zhang [94] developed the material performance indices and procedures to guide the systematic material selection for multi-material automotive bodies. Qiu et al. [95] built a hybrid optimization model for material selection. The aim of the model was to minimizing environmental impact considering the discrete variable of materials. In this category, the function of indices is to quantitatively measure the eco-impact of different materials to achieve environmentally conscious material selection.

\section{2) Modeling and evolutionary optimization}

How to modeling the material selection problem, and using what kinds of algorithm to solve these models were also considered. Zhang et al. [96] developed a detailed approach and its corresponding software prototype for selecting optimal material constituent compositions and microstructures. Antonio [97] proposed a multi-objective optimization framework to the optimal design of hybrid composite structures with sizing, topology and material selection. Further, a fuzzy interface system combined with genetic algorithm was developed to optimize the multi-objective problem in the selection of recyclable materials [98]. Note that the researchers tend to implement the MS models in software to provide computeraided MS tools.

\section{3) Multi-criteria decision making and design workflows}

Some MS problems were solved by multi-criteria decision making (MCDM) and proposed design frameworks. Huang et al. [99] presented a MCDM model and uncertainty analysis method for the environmentally conscious materials selection problem. The Z-transformation was introduced in material selection for scaling the material properties [100]. Zarandi et al. [101] translated the expert knowledge to decision making rules, where a decision tree was developed to guide the choice. Albinana and Vila [102] draw up a framework for integrated materials and process selection in product conceptual design phase. Sakundarini et al. [103] presented a multi-material selection method for lightweight design, which incorporated recyclability for an automotive body assembly. In this category, to solve the MS problem in several following steps will lower the modeling and computing complexity, and provide frameworks for material selection.

\section{B. Environmental evaluation for specific materials}

Some researchers focused on the eco-performance evaluation for critical materials in their use phase. Jastorff et al. [104] described new and updated findings regarding a sustainable product design for ionic liquids, where an ecodesign scheme for these liquids was also proposed by them. Yen and Chen [105] presented an approach to evaluating the toxic potential for products or materials using Chineselanguage material safety data sheets. Köhler [106] discussed strategies for eco-design of e-textiles focusing on waste prevention. Pehlken et al. [107] gave advice on how to cope with uncertainties by reaching the goal of achieving a constant product quality in feed processing. It is noticed that critical raw materials, toxic materials, or large-scale material flows have been focused by researchers to provide safety and sustainable product supply.

\section{SOFTWARE TOOLS IN PRODUCT ECO-DESIGN}

Eco-design software tools have been developed to reducing the product environmental impact throughout all stages of their life cycle. Vallet and Eynard [108] compared the actual commercial eco-design software with ordinary design software. Birch et al. [109] analyzed the output mechanisms of different DFE tools, and pointed out that strategy-specific tools are changing to be product-specific tools. Table 3 is composed to list the typical non-commercial eco-design software tools during $2005-2015$.

Following findings were inferred from the analysis of Table 3. First, knowledge base [110] was used as a bottom supporting basis in eco-design software. The knowledge base stored the eco-design rules, guidelines, and processes to help the decision-making in eco-software. It is a useful approach to reuse expert experience when the design information is insufficient in early design stage. But how to update the ecological knowledge base conveniently still need to be further studied. Second, eco-design tools are eager to be combined with commercial CAD software to ease the eco-performance 
analysis [111-114]. For instance, the materials' eco-impact analysis in parts, disassembly movement analysis, and material compatibility analysis in DFR had been achieved by ecodeveloped CAD. To increase the analysis functions and improve its suitability for different products are the future direction of eco-CAD. Further, eco-design software tools based on a framework and several stages have been developed [115, 116]. They tend to be independent software to solve eco-design tasks such as data management, eco-innovation, and ecomaterial selection together. Thus, they are suit to be improved to generate commercial eco-design software for industries.

Table 3 List of eco-design software tools

\begin{tabular}{|l|l|}
\hline Description & Contribution \\
\hline $\begin{array}{l}\text { Knowledge } \\
\text { management system for } \\
\text { eco-design [110] }\end{array}$ & $\begin{array}{l}\text { Two parts including an eco-design } \\
\text { process reference model and } \\
\text { personalisation strategy }\end{array}$ \\
\hline $\begin{array}{l}\text { Integrated eco-design } \\
\text { tool [111] }\end{array}$ & $\begin{array}{l}\text { Including databases, perspective tools, } \\
\text { and analytical tools }\end{array}$ \\
\hline $\begin{array}{l}\text { Eco-design based on } \\
\text { CAX systems [112] }\end{array}$ & $\begin{array}{l}\text { Eco-design tool based on feature } \\
\text { technology and CAD/CAM/CAPP/PLM }\end{array}$ \\
\hline EcoCAD tool [113] & $\begin{array}{l}\text { To improve material toxicity and ease of } \\
\text { disassembly, combined with CAD }\end{array}$ \\
\hline $\begin{array}{l}\text { Disassembly direction } \\
\text { analysis tool [114] }\end{array}$ & $\begin{array}{l}\text { Integrated with SolidWorks to generate } \\
\text { feasible disassembly directions }\end{array}$ \\
\hline iTree [115] & $\begin{array}{l}\text { Combining eco-design and TRIZ together } \\
\text { to create eco-design guidelines }\end{array}$ \\
\hline SPICE [116] & $\begin{array}{l}\text { Aiding strategic design management and } \\
\text { material selection for eco-design }\end{array}$ \\
\hline
\end{tabular}

\section{CONCLUSIONS}

The environmentally conscious product design in the last decade was systematically reviewed from the following five aspects. They are product eco-design, design for disassembly, design for recycling, material selection, and eco-design software tools. Some findings were obtained from the review that: a) eco-performance assessment of products have been implemented as a first step to product eco-design or ecoinnovation. b) Multi-objective modeling and evolutionary optimization have been used in eco-design to balance the product eco-performance and life cycle cost. c) Disassembly sequencing was solved in parts connection, disassembly time, cost, and uncertainty factors, respectively. d) Disassembly line balancing problem was focused to build automatic disassembly line. $e$ ) Products and materials were researched to be recycled with thermodynamic or mechanical approaches. f) Material selections for products were studied with material eco-impact assessment. $g$ ) Eco-design projects and software tools are being developed around the world in multiple industries with global co-operations.

Though a lot of work have been done in ECPD, there are some aspects that are still lacking in this subject. The following three problems still waiting to be focused are put forward to promote ECPD:

a) How to introduce the definition of resource efficiency to product eco-design to form architecture for design for resource efficiency (DFRE)? Though it is known that promoting resource efficiency will lower material usage and generate less waste, how to assess resource efficiency and how to design

product with improved life cycle resource efficiency still needs future work.

b) How to improve or guarantee the environmental performance of a family of products, rather than focused on a single product? Currently, engineers always develop a product platform rather than a single product. To combine the theories and methods in product family design and product eco-design together still needs more focus.

c) How to use integrated information techniques to support innovative design and redesign and guarantee the ecoperformance of products? As we all know, design modeling and methods researches will finally located in the development of computer-aided design software tools. To provide integrated eco-design software for different industries are still an important work in the near future.

The morphological analysis and box method will be used in our next work for analyzing product sustainable development strategies. The future research directions for ECPD will lie in that the product eco-design for resource efficiency, ecoplatform based product family design research, and product eco-design by information technology.

\section{ABBREVIATIONS}

AHP

D4S

DEA

DFD

DFE

DFR

DFRE

DLBP

DSM

ECMPRO

Eco-design

ECPD

ECQFD

EOL

FAHP

GA

GM

LCA

LCC

LCE

LCIA

LCP

MCDM

MFA

MS

QFD

QFDE

RRN

TOPSIS

TRIZ
Analytical hierarchical process

Design for sustainability

Data envelopment analysis

Design for disassembly

Design for environment

Design for recycling

Design for resource efficiency

Disassembly line balancing problem

Design structure matrix

Environmentally conscious manufacturing and product recovery

Ecological design

Environmentally conscious product design Environmentally conscious quality function deployment

End-of-life

Fuzzy AHP

Genetic algorithm

Green modularization

Life cycle assessment

Life cycle cost

Life cycle engineering

Life cycle impact analysis

Life cycle planning

Multi-criteria decision making

Material flow analysis

Material selection

Quality function deployment

Quality function deployment for environment

Reuse and recycling network

Technique for order preference by similarity to ideal solution

Theory of inventive problem solving 


\section{ACKNOWLEDGEMENT}

This work is financially supported by the National Natural Science Foundation of China under Grant 51475459, the Fundamental Research Funds for the Central Universities of China under Grant 2012QNB15, and the Priority Academic Program Development of Jiangsu Higher Education Institutes under Grant PAPD.

\section{REFERENCES}

[1] M. A. Ilgin, and S. M. Gupta, "Environmentally conscious manufacturing and product recovery (ECMPRO): A review of the state of the art," J. Environ. Manage., vol. 91, pp. 563-591, Jan-Feb 2010.

[2] J. H. Li, X. L. Zeng, and A. Stevels, "Ecodesign in consumer electronics: past, present, and future," Crit. Rev. Env. Sci. Tec., vol. 45 , pp. 840-860, Apr 2015.

[3] D. Kralisch, D. Ott, and D. Gericke, "Rules and benefits of Life Cycle Assessment in green chemical process and synthesis design: a tutorial review," Green Chem., vol. 17, pp. 123-145, 2015.

[4] K. Ramani, D. Ramanujan, W. Z. Bernstein, et al., "Integrated sustainable life cycle design: a review," J. Mech. Design., vol. 132, pp. 1-15, Sep 2010.

[5] R. Bogue, "Design for disassembly: a critical twenty-first century discipline," Assembly Autom., vol. 27, pp. 285-289, 2007.

[6] P. S. Ramalhete, A. M. R. Senos, and C. Aguiar, "Digital tools for material selection in product design," Mater. Design, vol. 31, pp. 2275 2287, May 2010.

[7] Y. Kobayashi, H. Kobayashi, A. Hongu, et al., "A practical method for quantifying eco-efficiency using eco-design support tools," J. Ind. Ecol., vol. 9, pp. 131-144, 2005.

[8] C. Cerdan, C. Gazulla, M. Raugei, et al., "Proposal for new quantitative eco-design indicators: a first case study," J. Clean. Prod., vol. 17, pp. 1638-1643, Dec 2009.

[9] J. H. Park, and K. K. Seo, "A knowledge-based approximate life cycle assessment system for evaluating environmental impacts of product design alternatives in a collaborative design environment," Adv. Eng. Inform., vol. 20, pp. 147-154, Apr 2006.

[10] H. K. Chan, X. J. Wang, G. R. T. White, et al., "An extended fuzzyAHP approach for the evaluation of green product designs," Ieee. T. Eng. Manage., vol. 60, pp. 327-339, May 2013.

[11] T. C. Kuo, S. H. Chang, and S. H. Huang, "Environmentally conscious design by using fuzzy multi-attribute decision-making," Int. J. Adv. Manuf. Tech., vol. 29, pp. 209-215, Jun 2006.

[12] T. A. Chiang, Z. H. Che, and T. T. Wang, "A design for environment methodology for evaluation and improvement of derivative consumer electronic product development," J. Syst. Sci. Syst. Eng., vol. 20, pp. 260-274, Sep 2011.

[13] V. N. Ajukumar, and O. P. Gandhi, "Evaluation of green maintenance initiatives in design and development of mechanical systems using an integrated approach," J Clean Prod, vol. 51, pp. 34-46, Jul 152013.

[14] L. Zhang, Y. Zhan, Z. F. Liu, et al., "Development and analysis of design for environment oriented design parameters," J. Clean. Prod., vol. 19 , pp. 1723-1733, Oct 2011

[15] T. Sakao, "A QFD-centred design methodology for environmentally conscious product design," Int. J. Prod. Res., vol. 45, pp. 4143-4162, 2007.

[16] S. Vinodh, and G. Rathod, "Integration of ECQFD and LCA for sustainable product design," J. Clean. Prod., vol. 18, pp. 833-842, 2010.

[17] A. Romli, P. Prickett, R. Setchi, et al., "Integrated eco-design decisionmaking for sustainable product development," Int. J. Prod. Res., vol. 53, pp. 549-571, Jan 172015.

[18] S. Vinodh, and G. Rathod, "Application of fuzzy logic-based environmental conscious QFD to rotary switch: a case study," Clean. Technol. Envir., vol. 14, pp. 319-332, Apr 2012.

[19] C. S. Li, X. P. Zhang, S. J. Zhang, et al., "Environmentally conscious design of chemical processes and products: Multi-optimization method," Chem. Eng. Res. Des., vol. 87, pp. 233-243, Feb 2009.

[20] J. C. P. Su, C. H. Chu, and Y. T. Wang, "A decision support system to estimate the carbon emission and cost of product designs," Int. J. Precis. Eng. Man., vol. 13, pp. 1037-1045, Jul 2012.
[21] C. Achillas, D. Aidonis, C. Vlachokostas, et al., "Re-designing industrial products on a multi-objective basis: a case study," J. Oper. Res. Soc., vol. 64, pp. 1336-1346, Sep 2013.

[22] S. R. Lim, Y. R. Kim, S. H. Woo, et al., "System optimization for ecodesign by using monetization of environmental impacts: a strategy to convert bi-objective to single-objective problems," J. Clean. Prod., vol. 39, pp. 303-311, Jan 2013.

[23] H. Kobayashi, "A systematic approach to eco-innovative product design based on life cycle planning," Adv. Eng. Inform., vol. 20, pp. 113-125, Apr 2006.

[24] T. A. Chiang, and R. Roy, "An intelligent benchmark-based design for environment system for derivative electronic product development," Comput. Ind., vol. 63, pp. 913-929, Dec 2012.

[25] J. R. Chou, "An ARIZ-based life cycle engineering model for ecodesign," J. Clean. Prod., vol. 66, pp. 210-223, Mar 12014.

[26] S. Vinodh, V. Kamala, and K. Jayakrishna, "Integration of ECQFD, TRIZ, and AHP for innovative and sustainable product development," Appl. Math. Model., vol. 38, pp. 2758-2770, Jun 2014.

[27] M. Sandberg, P. Boart, and T. Larsson, "Functional product life-cycle simulation model for cost estimation in conceptual design of jet engine components," Concurrent Eng.-Res. A., vol. 13, pp. 331-342, Dec 2005.

[28] B. Kayis, G. Arndt, M. Zhou, et al., "Risk quantification for new product design and development in a concurrent engineering environment," Cirp. Ann.-Manuf. Techn., vol. 55, pp. 147-150, 2006.

[29] M. Sy, and C. Mascle, "Product design analysis based on life cycle features," J. Eng. Design, vol. 22, pp. 387-406, 2011.

[30] C. H. Lo, "An extension design by applying patent map analysis on product life cycle," Pak. J. Stat., vol. 29, pp. 769-784, Nov 2013.

[31] H. Kobayashi, "Strategic evolution of eco-products: a product life cycle planning methodology," Res. Eng. Des., vol. 16, pp. 1-16, Nov 2005.

[32] J. R. Bradley, and H. H. Guerrero, "Product design for life-cycle mismatch," Prod. Oper. Manag., vol. 17, pp. 497-512, Sep-Oct 2008.

[33] P. Knight, and J. O. Jenkins, "Adopting and applying eco-design techniques: a practitioners perspective," J. Clean. Prod., vol. 17, pp. 549-558, 2009

[34] C. Telenko, and C. C. Seepersad, "A methodology for identifying environmentally conscious guidelines for product design," J. Mech. Design, vol. 132, pp. Sep 2010.

[35] S. Gonzalez-Garcia, F. J. Silva, M. T. Moreira, et al., "Combined application of LCA and eco-design for the sustainable production of wood boxes for wine bottles storage," Int. J. Life Cycle Ass., vol. 16, pp. 224-237, Mar 2011.

[36] F. Zhang, M. Rio, R. Allais, et al., "Toward an systemic navigation framework to integrate sustainable development into the company," J. Clean. Prod., vol. 54, pp. 199-214, Sep 2013.

[37] H. E. Tseng, C. C. Chang, and J. D. Li, "Modular design to support green life-cycle engineering," Expert. Syst. Appl., vol. 34, pp. 25242537, May 2008.

[38] S. R. Yu, Q. Y. Yang, J. Tao, et al., "Product modular design incorporating life cycle issues - Group Genetic Algorithm (GGA) based method," J. Clean. Prod., vol. 19, pp. 1016-1032, Jun-Jul 2011.

[39] J. H. Yan, C. H. Feng, and K. Cheng, "Sustainability-oriented product modular design using kernel-based fuzzy c-means clustering and genetic algorithm," P. I. Mech. Eng. B-J. Eng., vol. 226, pp. 1635-1647, Oct 2012.

[40] X. Q. Qian, and H. C. Zhang, "Design for environment: an environmentally conscious analysis model for modular design," Ieee T. Electron. Pack., vol. 32, pp. 164-175, Jul 2009.

[41] T. R. Chang, C. S. Wang, and C. C. Wang, "A systematic approach for green design in modular product development," Int. J. Adv. Manuf. Tech., vol. 68, pp. 2729-2741, Oct 2013.

[42] Y. Umeda, S. Fukushige, K. Tonoike, et al., "Product modularity for life cycle design," Cirp Ann.-Manuf. Techn., vol. 57, pp. 13-16, 2008.

[43] Q. Y. Yang, S. R. Yu, and A. Sekhari, "A modular eco-design method for life cycle engineering based on redesign risk control," Int. J. Adv. Manuf. Tech., vol. 56, pp. 1215-1233, Oct 2011.

[44] Y. J. Ji, X. B. Chen, G. N. Qi, et al., "Modular design involving effectiveness of multiple phases for product life cycle," Int. J. Adv. Manuf. Tech., vol. 66, pp. 1475-1488, 2012. 
[45] H. E. Tseng, C. C. Chang, and C. J. Cheng, "Disassembly-oriented assessment methodology for product modularity," Int. J. Prod. Res., vol. 48, pp. 4297-4320, 2010.

[46] W.-H. Chung, G. E. Okudan Kremer, and R. A. Wysk, "A Modular Design Approach to Improve Product Life Cycle Performance Based on the Optimization of a Closed-Loop Supply Chain," J. Mech. Des., vol. 136, pp. 021001, 2013.

[47] Q. Y. Yang, S. R. Yu, and D. Jiang, "A modular method of developing an eco-product family considering the reusability and recyclability of customer products," J. Clean. Prod., vol. 64, pp. 254-265, Feb 12014.

[48] N. Tchertchian, D. Millet, and O. Pialot, "Modifying module boundaries to design remanufacturable products: the modular grouping explorer tool," J. Eng. Design, vol. 24, pp. 546-574, Aug 2013.

[49] Y. M. Huang, and Y. C. Liao, "Disassembly processes with disassembly matrices and effects of operations," Assembly Autom., vol. 29, pp. 348-357, 2009.

[50] H. Wu, and H. F. Zuo, "Using genetic/simulated annealing algorithm to solve disassembly sequence planning," J. Syst. Eng. Electron., vol. 20, pp. 906-912, Aug 2009.

[51] R. Edmunds, M. Kobayashi, and M. Higashi, "Using constraintsatisfaction to optimise disassembly sequences generated from AND/OR information," Int. J. Prod. Res., vol. 50, pp. 4105-4126, 2012.

[52] L. M. Qiu, X. J. Liu, S. Y. Zhang, et al., "Disassemblability Modeling Technology of Configurable Product Based on Disassembly Constraint Relation Weighted Design Structure Matrix(DSM)," Chin. J. Mech. Eng.-En., vol. 27, pp. 511-519, May 2014

[53] K. Xia, L. Gao, W. D. Li, et al., "Disassembly sequence planning using a simplified Teaching-Learning-Based Optimization algorithm," Adv. Eng. Inform., vol. 28, pp. 518-527, Oct 2014.

[54] J. Ko, E. Nazarian, H. Wang, et al., "An assembly decomposition model for subassembly planning considering imperfect inspection to reduce assembly defect rates," J. Manuf. Syst., vol. 32, pp. 412-416, Jul 2013.

[55] K. Banda, and I. Zeid, "To disassemble or not: a computational methodology for decision making," J. Intell. Manuf., vol. 17, pp. 621634, Oct 2006

[56] G. D. Tian, M. C. Zhou, J. W. Chu, et al., "Probability evaluation models of product disassembly cost subject to random removal time and different removal labor cost," Ieee T. Autom. Sci. Eng., vol. 9, pp. 288-295, Apr 2012

[57] M. Tripathi, S. Agrawal, M. K. Pandey, et al., "Real world disassembly modeling and sequencing problem: Optimization by Algorithm of SelfGuided Ants (ASGA)," Robot. Cim.-Int. Manuf., vol. 25, pp. 483-496, Jun 2009

[58] Y. S. Ma, H. B. Jun, H. W. Kim, et al., "Disassembly process planning algorithms for end-of-life product recovery and environmentally conscious disposal," Int. J. Prod. Res., vol. 49, pp. 7007-7027, 2011

[59] T. F. Go, D. A. Wahab, M. N. Ab Rahman, et al., "Genetically optimised disassembly sequence for automotive component reuse," Expert Syst. Appl., vol. 39, pp. 5409-5417, Apr 2012.

[60] S. Behdad, and D. Thurston, "Disassembly and reassembly sequence planning tradeoffs under uncertainty for product maintenance," J. Mech. Design, vol. 134, pp. Apr 2012.

[61] G. D. Tian, Y. M. Liu, Q. Z. Tian, et al., "Evaluation model and algorithm of product disassembly process with stochastic feature," Clean Technol. Envir., vol. 14, pp. 345-356, Apr 2012.

[62] H. F. Wang, and Y. S. Huang, "A two-stage robust programming approach to demand-driven disassembly planning for a closed-loop supply chain system," Int. J. Prod. Res., vol. 51, pp. 2414-2432, Apr 2013.

[63] S. Behdad, L. Berg, J. Vance, et al., "Immersive computing technology to investigate tradeoffs under uncertainty in disassembly sequence planning," J. Mech. Design, vol. 136, pp. Jul 2014.

[64] S. Behdad, M. Kwak, H. Kim, et al., "Simultaneous selective disassembly and end-of-life decision making for multiple products that share disassembly operations," J. Mech. Design, vol. 132, pp. Apr 2010 .

[65] S. Smith, G. Smith, and W. H. Chen, "Disassembly sequence structure graphs: An optimal approach for multiple-target selective disassembly sequence planning," Adv. Eng. Inform., vol. 26, pp. 306-316, Apr 2012.

[66] H. J. Han, J. M. Yu, and D. H. Lee, "Mathematical model and solution algorithms for selective disassembly sequencing with multiple target components and sequence-dependent setups," Int. J. Prod. Res., vol. 51, pp. 4997-5010, Aug 2013.

[67] J. L. Rickli, and J. A. Camelio, "Multi-objective partial disassembly optimization based on sequence feasibility," J. Manuf. Syst., vol. 32, pp. 281-293, Jan 2013.

[68] X. W. Song, W. D. Zhou, X. X. Pan, et al., "Disassembly sequence planning for electro-mechanical products under a partial destructive mode," Assembly Autom., vol. 34, pp. 106-114, 2014.

[69] A. Aydemir-Karadag, and O. Turkbey, "Multi-objective optimization of stochastic disassembly line balancing with station paralleling," Comput Ind. Eng., vol. 65, pp. 413-425, Jul 2013

[70] S. Avikal, R. Jain, and P. K. Mishra, "A Kano model, AHP and MTOPSIS method-based technique for disassembly line balancing under fuzzy environment," Appl. Soft. Comput., vol. 25, pp. 519-529, Dec 2014.

[71] M. L. Bentaha, O. Battaia, and A. Dolgui, "A sample average approximation method for disassembly line balancing problem under uncertainty," Comput. Oper. Res., vol. 51, pp. 111-122, Nov 2014.

[72] R. A. Williams, and X. Jia, "Digital visual simulation for design of mineral and metal recycling processes and of secondary products," Miner. Eng., vol. 20, pp. 933-938, Aug 2007.

[73] E. Brouillat, and V. Oltra, "Extended producer responsibility instruments and innovation in eco-design: An exploration through a simulation model," Ecol. Econ., vol. 83, pp. 236-245, Nov 2012.

[74] C. Chen, and L. Q. Liu, "Pricing and quality decisions and financial incentives for sustainable product design with recycled material content under price leadership," Int. J. Prod. Econ., vol. 147, pp. 666-677, Jan 2014.

[75] D. Rochat, C. R. Binder, J. Diaz, et al., "Combining Material Flow Analysis, Life Cycle Assessment, and Multiattribute Utility Theory Assessment of End-of-Life Scenarios for Polyethylene Terephthalate in Tunja, Colombia," J. Ind. Ecol., vol. 17, pp. 642-655, Oct 2013.

[76] A. van Schaik, and M. A. Reuter, "The use of fuzzy rule models to link automotive design to recycling rate calculation," Minerals Engineering, vol. 20, pp. 875-890, 2007.

[77] A. van Schaik, and M. A. Reuter, "Dynamic modelling of E-waste recycling system performance based on product design," Minerals Engineering, vol. 23, pp. 192-210, 2010.

[78] M. Reuter, and A. van Schaik, "Opportunities and limits of recycling: A dynamic-model-based analysis," Mrs Bull., vol. 37, pp. 339-347, Apr 2012.

[79] G. Gaustad, E. Olivetti, and R. Kirchain, "Design for Recycling," J. Ind. Ecol., vol. 14, pp. 286-308, Mar-Apr 2010.

[80] C. Hageluken, and C. W. Corti, "Recycling of gold from electronics: Cost-effective use through 'Design for Recycling'," Gold Bull., vol. 43 , pp. 209-220, 2010

[81] N. Perry, A. Bernard, F. Laroche, et al., "Improving design for recycling - Application to composites," Cirp Ann.-Manuf. Techn., vol. 61, pp. 151-154, 2012

[82] P. Corabieru, A. Corabieru, and D. D. Vasilescu, "New approaches in the design of plastic products for easy recycling," Environ. Eng. Manag. J., vol. 13, pp. 1997-2004, Aug 2014.

[83] C. A. McMillan, S. J. Skerlos, and G. A. Keoleian, "Evaluation of the metals industry's position on recycling and its implications for environmental emissions," J. Ind. Ecol., vol. 16, pp. 324-333, Jun 2012.

[84] K. Sivaprasad, and C. G. Nandakumar, "Design for ship recycling," Ships Offshore Struc., vol. 8, pp. 214-223, Apr 2013.

[85] J. Tian, and M. Chen, "Sustainable design for automotive products dismantling and recycling of end-of-life vehicles," Waste Manag., vol. 34, pp. 458-467, Feb 2014.

[86] E. Dace, G. Bazbauers, A. Berzina, et al., "System dynamics model for analyzing effects of eco-design policy on packaging waste managemen system," Resour. Conserv. Recy., vol. 87, pp. 175-190, Jun 2014.

[87] P. Erol, and J. Thoming, "ECO-design of reuse and recycling networks by multi-objective optimization," J. Clean. Prod., vol. 13, pp. 1492 1503, 2005.

[88] Z. F. Qin, and X. Y. Ji, "Logistics network design for product recovery in fuzzy environment," Eur. J. Oper. Res., vol. 202, pp. 479-490, Apr 2010.

[89] K. Alaykiran, and E. Guner, "A mathematical model for multi-product recycling network design," J. Fac. Eng. Archit. Gaz., vol. 28, pp. 151 159, Mar 2013 
[90] S. G. Kit, S. R. W. Alwi, and Z. A. Manan, "A new graphical approach for simultaneous targeting and design of a paper recycling network," Asia-Pac. J. Chem. Eng., vol. 6, pp. 778-786, Sep-Oct 2011.

[91] M. Fröhling, F. Schwaderer, H. Bartusch, et al., "A Material Flowbased Approach to Enhance Resource Efficiency in Production and Recycling Networks," J. Ind. Ecol., vol. 17, pp. 5-19, 2013.

[92] B. Vahdani, and M. Naderi-Beni, "A mathematical programming model for recycling network design under uncertainty: an interval-stochastic robust optimization model," Int. J. Adv. Manuf. Tech., vol. 73, pp. 1057-1071, Jul 2014

[93] H. H. Huang, Z. F. Liu, L. Zhang, et al., "Materials selection for environmentally conscious design via a proposed life cycle environmental performance index," Int. J. Adv. Manuf. Tech., vol. 44, pp. 1073-1082, Oct 2009.

[94] X. T. Cui, H. W. Zhang, S. X. Wang, et al., "Design of lightweight multi-material automotive bodies using new material performance indices of thin-walled beams for the material selection with crashworthiness consideration," Mater. Design, vol. 32, pp. 815-821, Feb 2011.

[95] L. M. Qiu, L. F. Sun, X. J. Liu, et al., "Material selection combined with optimal structural design for mechanical parts," J. Zhejiang Univ.Sc. A, vol. 14, pp. 383-392, Jun 2013.

[96] X. J. Zhang, K. Z. Chen, and X. A. Feng, "Material selection using an improved Genetic Algorithm for material design of components made of a multiphase material," Mater. Design, vol. 29, pp. 972-981, 2008.

[97] C. A. C. Antonio, "Local and global Pareto dominance applied to optimal design and material selection of composite structures," Struct. Multidiscip. O., vol. 48, pp. 73-94, Jul 2013.

[98] N. Sakundarini, Z. Taha, S. H. Abdul-Rashid, et al., "Incorporation of high recyclability material selection in computer aided design," Mater. Design, vol. 56, pp. 740-749, Apr 2014.

[99] H. Huang, L. Zhang, Z. Liu, et al., "Multi-criteria decision making and uncertainty analysis for materials selection in environmentally conscious design," The International Journal of Advanced Manufacturing Technology, vol. 52, pp. 421-432, 2010.

[100] K. Fayazbakhsh, A. Abedian, B. D. Manshadi, et al., "Introducing a novel method for materials selection in mechanical design using Ztransformation in statistics for normalization of material properties," Mater. Design, vol. 30, pp. 4396-4404, Dec 2009.

[101] M. H. F. Zarandi, S. Mansour, S. A. Hosseinijou, et al., "A material selection methodology and expert system for sustainable product design," Int. J. Adv. Manuf. Tech., vol. 57, pp. 885-903, Dec 2011.

[102] J. C. Albinana, and C. Vila, "A framework for concurrent material and process selection during conceptual product design stages," Mater. Design, vol. 41, pp. 433-446, Oct 2012.
[103] N. Sakundarini, Z. Taha, S. H. Abdul-Rashid, et al., "Optimal multimaterial selection for lightweight design of automotive body assembly incorporating recyclability," Mater. Design, vol. 50, pp. 846-857, Sep 2013.

[104] B. Jastorff, K. Molter, P. Behrend, et al., "Progress in evaluation of risk potential of ionic liquids-basis for an eco-design of sustainable products," Green Chem., vol. 7, pp. 362-372, 2005.

[105] S. B. Yen, and J. L. Chen, "Calculation of a toxic potential indicator via Chinese-language material safety data sheets," J. Ind. Ecol., vol. 13, pp. 455-466, Jun 2009.

[106] A. R. Köhler, "Challenges for eco-design of emerging technologies: The case of electronic textiles," Materials \& Design, vol. 51, pp. 51-60, 2013.

[107] A. Pehlken, A. Decker, C. Kottowski, et al., "Energy efficiency in processing of natural raw materials under consideration of uncertainties," Journal of Cleaner Production, vol. pp. 2014.

[108] F. Vallet, B. Eynard, D. Millet, et al., "Using eco-design tools: An overview of experts' practices," Design Stud., vol. 34, pp. 345-377, May 2013.

[109] A. Birch, K. K. B. Hon, and T. Short, "Structure and output mechanisms in Design for Environment (DfE) tools," J. Clean. Prod., vol. 35, pp. 50-58, Nov 2012.

[110] V. Goepp, E. Caillaud, and B. Rose, "A framework for the design of knowledge management systems in eco-design," Int. J. Prod. Res., vol. 51, pp. 5803-5823, Oct 12013.

[111] J. L. Casamayor, and D. Z. Su, "Integration of eco-design tools into the development of eco-lighting products," J. Clean. Prod., vol. 47, pp. 3242, May 2013.

[112] R. Gaha, B. Yannou, and A. Benamara, "A New Eco-Design Approach on CAD Systems," Int. J. Precis. Eng. Man., vol. 15, pp. 1443-1451, Jul 2014.

[113] H. T. Chang, and C. H. Lu, "Simultaneous evaluations of material toxicity and ease of disassembly during electronics design integrating environmental assessments with commercial computer-aided design software," J. Ind. Ecol., vol. 18, pp. 478-490, Aug 2014.

[114] R. Iacob, and D. Popescu, "Generation of disassembly directions based on component mobility," Stud. Inform. Control., vol. 22, pp. 307-318, Dec 2013.

[115] D. Russo, C. Rizzi, and G. Montelisciani, "Inventive guidelines for a TRIZ-based eco-design matrix," J. Clean. Prod., vol. 76, pp. 95-105, Aug 2014.

[116] S. Prendeville, F. O'Connor, and L. Palmer, "Material selection for ecoinnovation: SPICE model," J. Clean. Prod., vol. 85, pp. 31-40, Dec 2014. 